\title{
Getting buy-in for climate change adaptation through urban planning: climate change communication as a multi-way process.
}

MABON, L. and SHIH, W.-Y. 
Getting buy-in for climate change adaptation through urban planning: climate change communication as a multi-way process

Leslie Mabon

School of Applied Social Studies, Robert Gordon University, Aberdeen, Scotland AB10 7QG

email: l.j.mabon@rgu.ac.uk

Wanyu Shih

Department of Urban Planning and Disaster Management, Ming-Chuan University, Gui Shan District, Taoyuan City 333, Taiwan

email:shih@mail.mcu.edu.tw

\begin{abstract}
The purpose of this chapter is to evaluate the role of communication in building support for climate change adaptation through urban spatial planning. We take Durban in South Africa as our case study, a city with significant vulnerability to climate change which is widely regarded as having successfully implemented climate adaptation initiatives through spatial planning, despite a challenging socio-economic context. In particular, we aim to assess the role of communication in initiating and sustaining Durban's climate adaptation initiatives, and evaluate wider lessons and challenges for the role of communication in climate change action with reference to social theory on science and environmental governance. We pay particular attention to the role of communication at the personal, institutional and municipal scale in eThekwini Municipality's Municipal Climate Protection Programme, focusing on framing and argumentation around the role the city's open space system plays in attaining ecosystem-based adaptation.
\end{abstract}

Drawing on a narrative literature review and associated content analysis of planning documentation and peer-reviewed literature, we argue that climate adaptation initiatives which carry multiple rationales in addition to the scientific basis for action stand the greatest chance of reaching implementation. We argue this is important because: (a) the complexity of governance structures mean many actors with different priorities and value positions must be engaged to enact policy; and (b) the short-term nature of political attention necessitates rationales that sustain their appeal to a broad range of viewpoints over time. We caution, however, that there is a need for ongoing critical reflection as to the grounds on which the 'success' of a climate adaptation intervention can be claimed, and that care must be taken to ensure a focus on framing and getting buy-in does not deflect attention away from debating the underlying causes of vulnerability.

Keywords: climate change adaptation; climate change communication; dialogue; urban greenspace; urban planning. 


\section{Introduction}

The purpose of this paper is to assess the role of communication in attaining climate change adaptation through urban spatial planning. The city scale is crucial for action on climate change. This is not only due to the rapidly urbanising nature of the world's population, but also because it is municipal and/or local governments who have the precision to put national- or international-level climate change policies into practice through processes such as building regulations and land use planning. Nonetheless, cities and their planning is an intrinsically complex issue (Crawford, 2016) which has given rise to calls for more communication between people and sectors (van Dijk and Ubels, 2016) to synthesise the range of knowledges and considerations at play. When one adds to this the complexities and uncertainties inherent in climate change, spatial planning becomes a good test case for assessing the value and limitations of multi-way climate change communication.

In this paper, we therefore evaluate how communication between sectors has helped to bring to fruition municipal climate change adaptation initiatives in Durban, South Africa. What makes Durban an even more valuable case study is the ability of eThekwini Municipality (the metropolitan municipality within which Durban is located) to instigate a suite of programmes for adapting to climate change through spatial planning in spite of a challenging socio-economic context. Through a narrative literature review of planning documentation and peer-reviewed literature relating to climate change adaptation in Durban, we aim to identify lessons which other cities may draw on for how communication can help to get support for their climate change initiatives. By extending this narrative review to include social science critiques of urban planning in Durban and of some concepts drawn on by eThekwini Municipality, however, our intention is to go beyond producing a 'best practice' guide and also flag up limitations or cautions for the role of climate change communication in the urban spatial planning context.

We hope this will be of value to decision-makers (municipal governments, local planners, community groups, practice-focused academics) tasked with actually having to implement climate change adaptation 'on the ground', and to academics wishing to develop a critical yet practically-focused approach to means of attaining cross-sector support for climate action. Through the use of a developing country case study, we hope to illustrate how momentum for climate change adaptation through urban planning can be sustained even in challenging socio-political contexts. However, we also encourage scholars and practitioners to continue to reflect on inequalities and power imbalances within which climate change communication may take place.

\section{Literature synthesis: communication as a multi-way process}

We understand climate change 'communication' as a multi-way exchange of ideas and opinions on the most appropriate way for society to respond to the problems raised by climate change, rather than a one-way transfer of information on the scientific basis for action. Bearing in mind that our interest is in how support may be built for evidence-based strategies for assessing risks and adapting to climate change, it is useful to look to science and technology studies literature to understand why 'communication' ought to be understood in this way. Wynne (1992) argues the 'information deficit' model of passing scientific information from experts out to society at large is an inadequate means of governing science in society. There are at least three reasons for this. One 
is that contemporary technical and scientific issues are very complex, meaning even 'experts' may disagree among themselves (Pellizzoni, 2003). A second is the decline in societal trust in the scientists and decision-makers previously entrusted to make decisions on society's behalf (Kasperson, 2014). A third is that new technologies and the knowledge on which they are based (including climate change mitigating technologies and policies) can have profound, far-reaching and potentially irreversible effects on how people can live their lives. This may include the cost and availability of low-carbon energy, or the extent to which people have to live with environmental change because of the success or otherwise of climate policies (Mabon et al, 2015).

In sum, science has profound effects on - and may be received in a number of different ways by society. There may therefore be a range of perspectives at play on what is considered an appropriate course of action in response to scientific knowledge. Processes like upstream engagement (Rogers-Hayden et al, 2007), co-production (Jasanoff, 2004), ‘opening up’ (Stirling, 2008) and 'heating up' (Sundqvist, 2014) have all emerged in social science. They have a common interest in fostering dialogue between science and society in order to take societal concerns into account alongside scientific knowledge in decision-making processes. In climate change-specific literature, this manifests itself in dialogic approaches which put at their core the kind of society created as a result of actions taken on the basis of scientific knowledge about climate change (e.g. Einsiedel et al, 2013; Escobar and Roberts, 2015; Vercelli et al, 2014).

This does not mean that 'anything goes' with regard to what constitutes valid knowledge, or that scientific knowledge is somehow less valuable than the other belief systems that may be at play (Wynne, 1996). However, there is a need to pay attention to the grounds on which different sections of society are actually concerned about an issue like climate change, and to acknowledge that concerns such as social justice (Shrader-Frechette, 2002), trust in decision-makers (Kasperson, 2014), connection to place (O'Neill, 2007) and morality or spirituality (Northcott, 2015) can influence actors' standpoints on climate change in addition to technical and scientific understanding. Discussions on climate change are therefore likely to involve a range of viewpoints and value systems, not all of which may buy into a 'pure science' rationale for taking action. The challenge is thus to ground communication in broad-based rationales which may facilitate agreement on practical action, even if more fundamental value disagreements remain (Mabon and Shackley, 2015). More practically, communication which gives a number of reasons for climate action with the potential to appeal to a range of constituencies can help to sustain policymakers' attention. This is crucial as the attention-cycle issue (Downs, 1972) has been argued to be equally applicable to climate change (UNEP, 2009). Finding framings and arguments that widen out the number of reasons for taking actions that have climate benefits may thus help to make rationales more durable and appealing when climate change is not a top political issue.

\section{Methodology}

The rationale behind this paper is to assess the role of communication in attaining climate change adaptation through urban spatial planning. To do this, the case study of Durban, South Africa is selected for two reasons. Firstly, it is widely held up as an exemplar of climate change adaptation through spatial planning (e.g. ASSAf, 2011). Secondly, the challenging social context of high 
unemployment, significant poverty and low life expectancy (eThekwini Municipality, 2010) means Durban may yield lessons for how to build and sustain momentum for urban climate change planning in the face of other pressing societal issues. In keeping with the argument in Section 2 that there may be a range of views on what constitutes an appropriate course of action on climate change, however, this paper also aims to scrutinise the grounds on which Durban's climate change adaptation initiatives may actually be considered examples of 'best practice'. Doing so entails assessing potential limitations or challenges for climate change communication raised by the Durban case study, through reference to social research carried out in Durban and also through engagement with underpinning social theory.

A narrative review was undertaken of both peer-reviewed and policy literature pertaining to climate change adaptation in Durban. Jones (2004) argues that narrative reviews of this nature are more appropriate than systematic literature reviews when the material being reviewed is itself qualitative in nature - as much of the material reporting the planning process for climate adaptation in Durban is. The reason for this, Jones argues, is that a narrative review allows the researcher to engage more flexibly with the stories contained in the qualitative material itself, and also to extend their survey to include 'grey' literature such as policy documents which lie outside the peer-reviewed literature but are nonetheless significant and influential. Moreover, given the overarching aim of engaging with the broader critical social science literature around planning and governance in Durban as well as the material specific to climate adaptation in the city, a narrative literature review was selected on account of the interpretative flexibility it gave to explore a new and potentially broad-reaching topic.

Selection and subsequent analytical guidelines were developed to address Green et al's (2006) critique that narrative literature reviews can tend towards haphazard sampling from the literature. Relevant peer-reviewed and policy documents were identified by searching in Google Scholar (scholar.google.com) with the terms 'Durban' and 'climate change adaptation' in the range from 1 January 2000 to 31 August 2016, excluding results discussing the Durban Adaptation Charter (which refers to local climate action globally) rather than climate adaptation in Durban specifically. To get a sense of the wider societal context into which Durban's planning for climate change adaptation occurred, Google Scholar was again searched over the same time periods for the terms 'Durban', 'society', and 'environment' and/or 'climate change', again excluding results referring to the Durban Adaptation Charter. This material was then further supplemented with policy documents produced by eThekwini Municipality referred to in the peer-reviewed articles, such as the Municipal Climate Protection Programme (eThekwini Municipality, 2010) and documentation on specific programmes. For the sampled texts, thematic analysis was then undertaken to identify relevant aspects of 'communication' as a dialogic process for decision-making about climate change. Four aspects in particular were drawn out of the reading: 1 . Key messages and frames used to justify climate adaptation actions; 2. Internal communication within eThekwini Municipality; 3. External communication between the municipality and other actors such as research institutes and private sector; and 4. Civil society participation in both adaptation initiatives and also decision-making processes. 
Following this model of a narrative review with thematic analysis therefore allowed for flexibility to draw in relevant material from outside a narrow 'climate change adaptation' sample, but at the same time retained a certain degree of rigour in the analysis and interpretation process. The aspects of the narrative review identified above - messaging, internal communication, external communication, and civil society participation - are now discussed in turn.

\section{Durban case study}

\subsection{Overview}

South Africa ranked 116th in the 2014 Human Development Index, which measures length and healthiness of life; knowledgeability; and quality of living standard (UNDP, 2015). This is reflected in the societal context of Durban which, despite making a significant contribution to South Africa's economy (ASSAf, 2011), still faces high unemployment, housing shortages and low life expectancy (eThekwini Municipality, 2010). For Durban, climate change therefore has the potential to intensify existing societal issues and can thus be considered a serious risk (Roberts and O'Donoghue, 2013).

Durban proposed a Municipal Climate Protection Programme (MCPP) in 2004 to respond to both adaptation and mitigation. Within this programme, ecosystem-based adaptation - the use of biodiversity and ecosystem services as part of an overall adaptation strategy - came to have an important role (Shih, 2016). The value of such an approach is argued to lie in its potential to produce multiple benefits (see Section 4.2.) and help frame the climate challenge at a municipal or local scale where fine-scale recommendations can be made (Roberts et al, 2012). Within Durban's MCPP, the Durban Metropolitan Open Space System (D'MOSS) came to be viewed as an available, cost-effective and sustainable means of coping with climate change, and indeed to act as an ecosystem-based adaptation strategy. D'MOSS is an interconnected green space system comprising ecologically valuable areas in both private- and public-owned lands. It was first developed in 1979 to protect important natural areas from urban development, but has evolved from these conservation-oriented roots to serve multiple functions (Shih, 2016). It is argued to be able to deliver several benefits at once: biodiversity conservation, environmental hazard reduction, carbon sequestration, and poverty elimination (Roberts et al, 2012). Given the potential for such benefits, we focus on the communication aspects of this more adaptation-focused iteration of the open space system in this section as well as providing analysis of communication in Durban's overall climate adaptation discussions.

\subsection{Framing and messaging}

The importance of climate change adaptation in Durban is framed within a much wider context of societal and environmental challenges in the city. The MCPP, for instance, argues that high unemployment, limited access to education, housing shortages and low life expectancy "increase the vulnerability of many of Durban's residents, and this situation is likely to be exacerbated as the impacts of climate change place further strain and demands on limited resources and infrastructure” (eThekwini Municipality, 2010: 3). Climate change is positioned not as a distant 
and unrelated phenomenon, but rather as something with the potential to have implications for poverty intensification, urbanisation and environmental deterioration in Durban (Roberts and O’Donoghue, 2013). Specific to ecosystem-based adaptation, justifications from eThekwini Municipality centre on 'win-win' outcomes with potential to achieve dual adaptation and mitigation; prevent biodiversity loss; and improve human wellbeing (Roberts et al, 2012). The value of broad-based rationales for climate change adaptation initiatives becomes even more important in the South African context, where concerns with social justice post-Apartheid continue (Smith, 2008). Understanding the value of climate change adaptation in terms of not undermining or losing development gains post-Apartheid can thus help to gain political traction (Roberts, 2010) in a way purely science-based arguments may not.

At the same time, however, decision-making for climate change adaptation through spatial planning remains firmly grounded in 'expert' scientific evidence. Freund (2001) notes the economic values assigned to D'MOSS are derived from environmental functions like temperature control and water cleansing. Indeed, eThekwini Municipality (2011a) explain that D'MOSS is "mapped by the Biodiversity Planning Branch of the Environmental Planning and Climate Protection Department (EPCPD) in consultation with relevant experts.” Whilst the messaging around climate change adaptation and indeed open space planning in Durban has shifted from science-driven to communicating societal benefit, the range of solutions and outcomes proposed are therefore in the first instance informed by a scientific evidence base. We return to this balancing of the scientifically appropriate with the socially acceptable in Section 5.

\subsection{Internal communication}

Communication within eThekwini Municipality has been a significant driver in determining the success or otherwise of Durban's climate change adaptation initiatives. There is emerging understanding that spatial planning for climate change adaptation requires cross-sectoral cooperation (Crawford, 2016). In the case of Durban, however, there is an ongoing need to build skills and capacity within government - especially outside the environmental protection sector - to allow engagement with the complexity of data and issues involved (Roberts et al, 2012). Linking back to Section 4.2., this reinforces the point that a dialogue between different standpoints as to the most appropriate course of action for climate change adaptation may still need to be informed by a basic common understanding of the scientific basis for action. Moreover, there are questions over how much the rhetoric of sustainability seen in Durban is backed up by financial commitment (Aylett, 2010) or supported in other government sectors (Bond and Dada, 2007), demonstrating the challenge of aligning goals within the organisation.

In a context of differing levels of knowledge and varying extents of support for climate change adaptation initiatives, the role of the individual in communication has been key in Durban. Freund (2001) believes individual 'champions' within the Municipality have been vital in affecting public consciousness and building support among decision-makers. Leck and Roberts (2015) see the informal interactions at the personal level departments - and indeed between sectors - as having a big influence on the success of climate change adaptation projects across Durban. Whilst Leck and Roberts (2015) admit such processes run the risk of being exclusionary, the fact adaptation projects 
have come to fruition through such processes illustrates Hajer and Kesselring's (1999) observation that under the right conditions, informal 'power brokering' can produce outcomes amenable to all.

Communication within eThekwini Municipality around spatial planning for climate change adaptation demonstrates that at different points in the planning process, different types of 'communication' may be appropriate. Sometimes this will be 'one-way' transfer of knowledge to build the basic capacity required for informed debate, sometimes it may be an individual leading based on personal conviction, and sometimes it may be less formal 'power brokering.' Just as Roberts et al (2012) note in the context of ecosystem-based adaptation that changes in the roles, responsibilities and functions of existing local government institutions may be required, so too may be different understandings of how internal communication ought to be undertaken depending on context.

\subsection{External communication}

Given our interest in the implementation of evidence-based strategies for adapting to climate change, we focus here on the role of knowledge in communication between institutions. The complexity of climate change and its interaction with environmental and social systems means data must be drawn in from a range of sources, necessitating targeted partnerships with research institutions (Roberts et al, 2012). This can be seen for water sector adaptation with the involvement of the University of Kwa-Zulu Natal in research into infrastructure and security (eThekwini Municipality, 2010), the involvement of 'relevant experts' in mapping D'MOSS (eThekwini Municipality, 2011a), and private sector organisations Green Roof Designs and Ecoman in preparing Durban's Guidelines for Green Roof Habitats (EThekwini Municipality, 2011b). The knock-on effect of this, however, is a need for local government to increase capacity in order to be able to use information of an academic and technical nature (Roberts et al, 2012) and for even more work to be done before civil society more widely can engage with sophisticated data (Aylett, 2010). In short, governing climate change adaptation processes inevitably entails the bringing together of different knowledge systems, hence communication between different actors will also entail the translation and interpretation of these different knowledges.

External communication around knowledge also entails managing relations with those whose immediate priorities may not directly relate to climate change. Roberts and O'Donoghue (2013) remind us that climate change is just one of many political issues in Durban, competing for attention with economic pressures and societal challenges, hence there may be value in linking climate protection to sustainable livelihoods, a 'green' economy, job creation and improvements in living standards. This serves as a reminder of the value of broad-based rationales for particular courses of spatial planning (e.g. poverty alleviation, biodiversity protection) which do not require one to immediately and directly connect with the 'pure science' knowledge basis for climate adaptation. Nevertheless, 'win win' situations may not always be possible. Roberts et al (2012) concede that there may have to be 'losers' at the individual level in order to attain outcomes which benefit Durban more broadly. It is the limitations of attempts to reach consensus, and the possibilities for civil society to intervene in this science-driven process, which we now address. 


\subsection{Civil society participation}

A key concern in Durban, intensified by high levels of poverty in the municipality, is civil society participation via building the ability of local communities themselves to adapt (Roberts, 2010). This has more recently developed into community-based ecosystem adaptation, which emphasises local benefits from climate actions (Douwes et al, 2015). An example of this is the Tree-Preneur programme associated with the Buffelsdraai Landfill Site Community Reforestation Project, where working with the Wildlands Conservation Trust NGO, unemployed community members are engaged as 'Tree-Preneurs' to grow trees which will be used for the reforestation project. The seedlings can then be exchanged for credit notes for food, basic goods and school fees (eThekwini Municipality, 2011c). Whilst the underlying aim of this project is carbon sequestration, it offers a number of other rationales which can be drawn on to get buy-in for the initiative - ecological restoration more generally, capacity building, engagement between government and civil society. All of these have the potential to provide pathways to societal support for a spatial planning initiative grounded in a 'scientific' rationale.

Whilst such initiatives are of course welcome in terms of alleviating poverty and developing local capacity, it is important to note their limitations. Much communication to civil society on climate change in Durban seems to be top-down and one-way in nature, with a focus on "message transfer" (Roberts, 2010: 409) and "effective communication" (Roberts et al, 2012). This in part may be explained by the need to provide basic knowledge to allow citizens to make informed decisions of their own about climate change action. However, it may also miss out on tapping into communities' rich local environmental knowledges and intimate understandings of ecosystems and their interactions (De Georges and Reilly, 2009) unless these communities have a means of participating in 'formal' knowledge-making processes. Moreover, in the context of Durban, Aylett (2010) criticises a constant drive for consensus in civil society engagement, arguing that conflict can drive innovation, identify weaknesses and find better solutions. Aylett illustrates this point with reference to implementation of improved air quality monitoring systems in Durban, which came about due to NGO efforts to draw attention to the air quality situation through protest and citizen monitoring rather than consensus.

As well as reinforcing the value of imagining climate adaptation actions which could get societal buy-in on a number of grounds, then, the nature of civil society engagement on spatial planning for climate change adaptation in Durban also raises dilemmas and challenges for climate change communication. One of these is the extent to which effective 'communication' needs to provide citizens with the knowledge to engage with climate change debates, versus designing processes that allow scientists and planners to tap into the rich knowledges local communities may already hold. The other is to question whether consensus always ought to be the aim of communication, or whether provoking debate - like Sundqvist's (2014) 'heating up' - might lead to better solutions. We now consider these more critical dimensions of climate change communication raised by the Durban case.

\section{Discussion}




\subsection{Framings}

Our first discussion point concerns what the social implications may be of the way in which a climate change debate is framed. In Durban, for instance, ecosystem services thinking has come to be central to understanding and demonstrating the value of the open space system to the city (eThekwini Municipality and ICLEI, 2007; Roberts et al, 2012). However, the ecosystem services concept more generally has faced criticism for thinking of ecosystems and the environment in the same monetary and capitalist terms which arguably contribute to societal inequalities in the first instance, and for ignoring justice concerns (Kosoy and Corbera, 2010; Matulis, 2014). Although the ecosystem services framing is clearly important for drawing attention to the value of Durban's open space, especially given the issues of poverty within the city, caution must be exercised not to deflect attention away from the social processes which may render some communities vulnerable in the first place. Communicating the value of climate change adaptation initiatives in terms of ecosystem services may engage a wider range of actors who may be more persuaded by economic arguments than environmental ones, but care has to be taken to ensure this does not inadvertently 'close down' the terms of the debate and exclude concerns over justice which may not so easily be quantified.

\subsection{Balancing the scientifically appropriate with the socially desirable}

In the case of Durban and the implementation of D'MOSS, the effects of a country-wide shift towards more democratic governance on environmental planning are noticeable. eThekwini Municipality's guidance on D'MOSS makes explicit mention that the council will not take ownership of land in the D'MOSS layer, and that the South African Constitution's statement that no one will be deprived of property rights is respected (eThekwini Municipality, 2011d). The expectation of 'democratic' decision-making hence restricts municipal government ability to zone or re-claim land for environmental protection purposes on the basis of scientific evidence alone. This should never be interpreted as a sign that democracy has negative effects. Rather, it demonstrates that in a democratic society, there is perhaps an expectation that communication on climate change decisions will be a multi-way process. In cases, this expectation that communication channels are opened to allow a range of perspectives to enter the decision-making process might rule out courses of action - like the automatic control of certain pieces of land within Durban - even though they appear technically superior. The ways in which D'MOSS in Durban has had to be adapted to take into account societal benefit and ecosystem services as well as biodiversity protection hence serves as a reminder that the spatial planning 'solutions' reached for climate change adaptation need to be socially acceptable as well as technically viable. The key lesson for climate change communication arising from this is to pay attention to whether the format and nature of communication fits with wider societal expectations on how the environment ought to be governed, and what may happen if it is not.

\subsection{Limitations and constraints}

We finish by acknowledging limitations and constraints of our work. One is the limited data available, especially on the societal dimensions of climate adaptation in Durban. Freund 
(2001:736) notes “(a)ny evaluation of environmental policy, let alone environmental awareness or developments on the ground, for post-apartheid Durban must inevitably be highly circumspect due to lack of data [...] and one's fear of being overly influenced by one influential opinion-maker or another." One must therefore exercise caution when using case studies like Durban as 'best practices' in climate change adaptation, and pay attention to the possibility of 'epistemic communities' (Haas, 1992; Toke, 1999) setting the terms of discussion on what constitutes 'successful' climate adaptation based on what they themselves consider to be valid knowledge and an appropriate range of outcomes. In other words, if places like Durban and projects like the Buffelsdraai Landfill Site Community Reforestation Project come to be described through academic and policy literature as exemplars of best practice, there remains a need for the research community to critically scrutinise who it is that is making such claims, what kind of evidence they use to ground their assertions, and what they stand to gain from communicating about the success of initiatives. This is especially true when claims to societal benefits such as 'poverty eradication' or 'improvement in quality of life' are made in reports and peer-reviewed literature. A literature-based review of the kind we have undertaken is constrained by the data available online. There is hence a need for ongoing critical social science research - ideally involving empirical or field components - that can help to question who is it that makes a judgement as to whether an intervention like stakeholder engagement has been successful, and evaluating the extent to which it an initiative may truly be considered a 'successful' example for others to follow.

Another constraint may be the nature of the narrative literature review itself. As Green et al (2006) point out, reviewing literature with the aim of interpreting and evaluating from it inevitably runs the risk of subjectivity. In addition to our suggestion of empirical social science research outlined above, subsequent assessments of climate adaptation in Durban may wish to undertake more structured systematic reviews, for instance setting specific research questions to be addressed through the review. Due to spatial constraints, we have also not fully explored the significant literature around climate change mitigation in Durban (e.g. Bond and Dada, 2007) which may offer further analogous examples on communication in municipal climate governance. Nonetheless, as a wide-ranging critical evaluation of the existing literature in order to draw out lessons and pitfalls for climate change communication in urban planning, we believe a narrative literature review is an appropriate starting point which may provide context and a basis for subsequent research.

\section{Conclusion}

In this chapter, we have assessed the role of communication in attaining climate change adaptation outcomes through urban spatial planning, focusing on the case of Durban in South Africa. Our key lessons are as follows:

- Climate change 'communication' should often be more than a one-way transfer of information. In Durban, spatial planning for climate adaptation requires communication between actors. This entails those responsible for putting spatial planning into action (municipal governments and urban planners) taking into consideration the concerns and 
priorities of other government departments, communities, developers, non-governmental organisations, citizens and others with a stake in planning actions undertaken;

- Framings which can build broad-based rationales for climate change actions may stand a greater chance of success. The messaging used in Durban around climate change adaptation and ecosystem-based adaptation in particular demonstrates how benefits of planning decisions such as poverty alleviation, disaster mitigation more generally, sustainable economic development or biodiversity protection can foster consensus for specific spatial decisions. Whilst there is of course a robust scientific basis for the actions which may be taken to mitigate or adapt to climate change, decision-makers need support from a range of institutions who may not buy in to 'pure science' rationales for climate change adaptation, or may have concerns grounded in economic, cultural or social values;

- alongside this drive for consensus and buy-in, there is a need for scholars of climate change communication to keep up their critical guard. This entails reflecting on which institutions are setting the terms of the discussion and to what effect; and where our attention may be diverted from the bigger structural issues which make communities vulnerable to climate change in the first place.

Above all else, there is a need in climate change communication to strike a balance between what is scientifically appropriate and what is socially acceptable. For both the 'science' and 'society' aspects, it is crucial to question who is involved in the communication process, who may be excluded, and to question who may benefit as a result of decisions taken. Retaining this healthy scepticism will help to ensure that an understanding of climate change communication as a dialogue between different value positions can be a force for good in getting buy-in and galvanising support for climate change adaptation through spatial planning.

Acknowledgements

The ideas and arguments in this paper were developed through a grant from the RGU Foundation received by Leslie Mabon, and a Japan Society for Promotion of Science (JSPS) Postdoctoral Fellowship held by Wanyu Shih.

\section{References}

Academy of Science of South Africa (ASSAf) (2011) Towards a low carbon city: Focus on Durban. Report of the ASSAf Consensus Study on Low Carbon Cities. ASSAf, Pretoria, South Africa

Aylett A (2010) Participatory planning, justice, and climate change in Durban, South Africa. Environment and Planning A 42:99-115

Bond P and Dada R (2007) A death in Durban: Capitalist patriarchy, global warming gimmickry and our responsibility for rubbish Agenda 73:46-56

Crawford R (2016) New Zealand Productivity Commission Research Note 2016/2: What can complexity theory tell us about urban planning? New Zealand Productivity Commission, Wellington 
De Georges PA and Reilly BK (2009) The Realities of Community Based Natural Resource Management and Biodiversity Conservation in Sub-Saharan Africa. Sustainability 1(3):734-788

van Dijk T and Ubels H (2016) How Dutch professionals conduct interactive design sessions to foster 'shared understanding'. Environment and Planning B: Planning and Design 43(3):464-479

Douwes D, Rouget M, Diederichs N, O’Donoghue S, Roy K, Roberts D (2015) Buffelsdraai Landfill Site Community Reforestation Project. XIV World Forestry Congress, 7 September 2015, Durban, South Africa.

Downs A (1972) Up and down with ecology - the issue-attention-cycle. The Public Interest 28:38-50

Einsiedel EF, Boyd AD, Medlock JE, Ashworth P (2013) Assessing socio-technical mindesets: Public deliberations on Carbon Capture and Storage in the context of energy sources and climate change. Energy Policy 53:149-158

EThekwini Municipality \& ICLEI Africa Secretariat (2007) Durban Biodiversity Report 2007. Local Action for Biodiversity (LAB) Report. EThekwini Municipality, Durban http://www.durban.gov.za/City_Services/development_planning_management/environmental_pl anning_climate_protection/Publications/Documents/Durbans\%20Biodiversity\%20Report\%2020 07.pdf

EThekwini Municipality (2010) Durban's Municipal Climate Protection Programme: Climate Change Adaptation Planning for a Resilient City. EThekwini Municipality, Durban http://www.durban.gov.za/City_Services/development_planning_management/environmental_pl anning_climate_protection/Publications/Documents/Durbans\%20Municipal\%20Climate\%20Prot ection\%20Programme_Climate\%20Chan.pdf

EThekwini Municipality (2011a) What is the Durban Metropolitan Open Space System? http://www.durban.gov.za/City_Services/development_planning_management/environmental_pl anning_climate_protection/Durban_Open_Space/Pages/-What-is-the-Durban-Metropolitan-Open -Space-System.aspx

EThekwini Municipality (2011b) Creating Space for Biodiversity in Durban: Guideline for Designing Green Roof Habitats. Durban, South Africa http://www.durban.gov.za/City_Services/development_planning_management/environmental_pl anning_climate_protection/Publications/Documents/Guideline\%20for\%20Designing\%20Green \%20Roof\%20Habitats1.pdf

EThekwini Municipality (2011c) Buffelsdraai Community Reforestation Project. http://www.durban.gov.za/City_Services/development_planning_management/environmental_pl anning_climate_protection/Projects/Pages/Buffelsdraai-Community-Reforestation-Project.aspx

EThekwini Municipality (2011d) Durban Metropolitan Open Space System FAQ. 
http://www.durban.gov.za/City_Services/development_planning_management/environmental_pl anning_climate_protection/Durban_Open_Space/Pages/MOSS_FAQ.aspx

Escobar O, Roberts JJ (2015) Citizens' Juries on Wind Farm Development in Scotland. ClimateXChange, Edinburgh

Freund R (2001) Brown and Green in Durban: The Evolution of Environmental Policy in a Post-Apartheid City International Journal of Urban and Regional Research 25(4):717-739

Google (n.d.) Google Scholar, scholar.google.com, accessed 03/10/2016.

Green BN, Johnson CD, Adams A (2001) Writing narrative literature reviews for peer-reviewed journals: secrets of the trade. Journal of Sports Chiropractic and Rehabilitation 15:5-19

Haas PM (1992) Introduction: epistemic communities and international policy coordination. International Organization 46(1):1-35

Hajer M, Kesselring S (1999) Democracy in the risk society? Learning from the new politics of mobility in Munich. Environmental Politics 8(3):1-23

Jasanoff S (2004) Science and citizenship: a new synergy. Science and Public Policy 31:90-94

Jones K (2004) Mission Drift in Qualitative Research, or Moving Toward a Systematic Review of Qualitative Studies, Moving Back to a More Systematic Narrative Review The Qualitative Report 9(1):95-112

Kasperson R (2014) Four questions for risk communication Journal of Risk Research 17(10):1233-1239

Kosoy N, Corbera E (2014) Payments for ecosystem services as commodity fetishism. Ecological Economics 69(6):1228-1246

Leck H, Roberts D (2015) What lies beneath: understanding the invisible aspects of municipal climate change governance. Current Opinion in Environmental Sustainability 13:61-67

Mabon L, Shackley S (2015) More than meeting the targets? The ethical dimensions of carbon dioxide capture and storage. Environmental Values 24:465-482

Mabon L, Shackley S, Vercelli S, Anderlucci J, Boot K (2015) Deliberative decarbonisation? Exploring a framework of ethical governance for low-carbon energy. Environment and Planning C: Government and Policy 33(2):256-271

Matulis BS (2014) The economic valuation of nature: a question of justice? Ecological Economics 104:155-157 
Northcott M (2015) Place, Ecology and the Sacred: The Moral Geography of Sustainable Communities. Bloomsbury, London

O’Neill J (2007) Markets, Deliberation and Environment. Routledge, London

Pellizzoni L (2003) Uncertainty and participatory democracy. Environmental Values 12(2):195-224

Roberts D (2010) Prioritizing climate change adaptation and local level resilience in Durban, South Africa. Environment and Urbanization 22(2):397-413

Roberts D, Boon R, Diederichs N, Douwes E, Govender N, McInnes A, McLean C, O'Donoghue S, Spires M (2012) Exploring ecosystem-based adaptation in Durban, South Africa: "learning-by-doing" at the local government coal face. Environment and Urbanization 24(1):167-195

Roberts D, O’Donoghue S.(2013) Urban environmental challenges and climate change action in Durban, South Africa. Environment and Urbanization 25(2):299-319

Rogers-Hayden T, Mohr A, Pidgeon N (2007) Introduction. Engaging with nanotechnologies: engaging differently. NanoEthics 1:123-130

Shih W (2016) Greenspace Planning for Climate Co-Benefits in Durban, South Africa. In: Doll $\mathrm{CNH}$, Puppim de Oliviera JA (eds) Urbanization and Climate Co-Benefits: Implementation of win-win interventions in cities. Routledge, London

Shrader-Frechette K (2002) Environmental Justice: Creating Equality, Reclaiming Democracy. Oxford University Press, New York

Smith L (2008) South African social work education: critical imperatives for social change in the post-apartheid and post-colonial context. International Social Work 51(3):371-383

Stirling A (2008) "Opening Up” and "Closing Down": Power, Participation, and Pluralism in the Social Appraisal of Technology. Science, Technology and Human Values 33(2):262-294

Sundqvist G (2014) 'Heating up' or 'Cooling Down'? Analysing and Performing Broadened Participation in Technoscientific Conflicts. Environment and Planning A 46(9):2065-2079

Toke D (1999) Epistemic communities and environmental groups. Politics 19(2):97-102

United Nations Development Programme (UNDP) (2015) Human Development Report 2015: Work for Human Development. UNDP, New York

United Nations Environment Programme (UNEP) (2011) IEA Training Manual Module 3: 2.4. Understanding Issue-Attention-Cycles. UNEP, New York Available: http://www.unep.org/ieacp/iea/training/manual/module3/1061.aspx 
Vercelli S, Battisti N, Dolcetti F, Ciesielska J, Barkved L, van der Panne G, Engen S, Provoost M (2014) Dialogue and Mutual Learning towards a Low Carbon Society - Experiences from 10 Countries Across Europe. Energy Procedia 58:30-35

Wynne B (1992) Misunderstood misunderstandings: social identities and public uptake of science. Public Understanding of Science 1:281-304

Wynne B (1996) May the sheep safely graze? A reflexive view of the lay-expert knowledge divide. In Lash S, Szerszynski B, Wynne B (eds) Risk, Envronment and Modernity: Towards a New Ecology. SAGE, London, pp 44-83 